\title{
PEIRCE E MILLIKAN: SISTEMA DE FUNÇÃO PRAGMÁTICO-SEMÂNTICA
}

\section{Tiziana Cocchieri}

Pontifícia Universidade Católica do Rio Grande do Sul - PUCRS, Doutorado em Filosofia. Porto Alegre, RS. E-mail: tiziana@unir.br

\section{RESUMO}

Neste artigo buscamos reconstruir a estrutura que permeia a unidade do conceito de teleofuncionalismo cunhado por Ruth Millikan, relacionando-o com a análise da estrutura fenomenológica apresentada por Charles S. Peirce. Ao elaborar seu modelo de configuração de mundo o filósofo descreve as categorias que compõem a realidade, a saber, Primeiridade, que corresponde ao que há de acaso, Secundidade, referente à alteridade no mundo e Terceridade, que é a regularidade percebida como lei. Nesse sentido, a natureza do significado sugere um substrato contextual, em que há uma conexão mediada entre mundo, pensamento e discurso. É em função desta temática que buscamos estabelecer um recorte de reflexão, apoiando-nos em reconstruções conceituais imbricadas à leitura de realidade.

Palavras-chave: Millikan. Peirce. Semiótica. Fenomenologia. Naturalismo Semântico.

\section{PEIRCE AND MILLIKAN: PRAGMATIC-SEMANTICS FUNCTION SYSTEM}

\begin{abstract}
In this article we seek to rebuild the structure that permeates the teleofuncionalismo concept unit coined by Ruth Millikan, relating it to the analysis of phenomenological structure by Charles $\mathrm{S}$. Peirce. When preparing your world configuration model the philosopher describes the categories that make up the reality, namely Firstness, which corresponds to what is random, Secondness, referring to the otherness in the world and thirdness, which is regularly perceived as law. Accordingly, the nature of the contextual meaning suggests a substrate, wherein there is a connection between mediated world, thinking and speech. It is due to this issue that we seek to establish a reflection clipping, relying on conceptual reconstructions imbricated to the reality of reading.
\end{abstract}

Keywords: Millikan. Peirce. Semiotics. Phenomenology. Naturalism Semantics. 


\section{INTRODUÇÃO}

De modo bastante geral, estamos equivocadamente habituados, através de uma tendência da mente de fixar crenças, a perceber que mente e mundo são elementos dissociados, em que as leis que operam no primeiro campo não sejam válidas para o segundo, o que em última análise desembocaria num modo de observar e entender o mundo de maneira fragmentada, de descrevê-lo de forma também fragmentada. Estas fragmentações são recorrentes no âmbito da formação escolar, em que o conhecimento é dividido, não correspondendo de modo efetivo ao tecido da realidade, pois as "placas" que delimitam as áreas de conhecimento não estão no mundo. De modo bastante geral, não são enfatizadas as associações entre mente e mundo na formação geral, não havendo esclarecimentos mais precisos sobre demarcações referentes à delimitações de zonas do conhecimento e suas respectivas finalidades, que servem para nos fazer discernir as coisas no mundo.

Nosso objetivo é compreender estas estruturas epistemológicas de forma sistemática, didático-pedagógica ou organizacional, partindo da busca dos critérios de delimitações de áreas de conhecimento em que somos conscientizados das idiossincrasias pertinentes ao processo de análise de áreas e objetos de pesquisa.

\section{MÉTODO}

Intentamos reconstruir uma perspectiva de descrição de realidade, proposta por Peirce, a partir das categorias que compõem a realidade, a saber: Primeiridade, Secundidade e Terceridade, relacionando-as às categorias correspondentes das formas de raciocínio lógico: abdução, indução e dedução. A reconstrução dessas categorias, assim como a ênfase em suas imbricações, nos fornecerão estofo para apresentarmos um esquema de como o mundo se estrutura, concatenando-o ao modelo cognitivo/linguístico proposto por Millikan, com intuito de configurar uma tessitura argumentativa que forneça subsídios na explicação de certo paralelismo entre mente e mundo em abordagem naturalista.

Considerando o princípio de inteligibilidade do cosmos, que está implícito na ideia de generalidade, a organização e reconhecimento de padrões ordenam a regularidade das coisas presentes no mundo e consequentemente da construção representacional e ação dos agentes.

As análises dos conceitos puros corroboram para a determinação da forma e reflexão de como diferem em multiplicidade o juízo sobre um objeto ou construto representacional, que possibilitam combinações inumeráveis, com possibilidade de que sejam compreendidos por meio de dados de valor semântico-cognitivo. Este princípio é concernente à base do nivelamento presente e representado na universalização de um juízo.

Esta pesquisa tem caráter de Pesquisa Qualitativa, visto que, não delimita visões isoladas, parciais e estanques de realidade, considerando o contexto dinâmico de fixação de crenças e formação de hábitos culturais, construindo e reconstruindo conceitos que corroboram para a compreensão e percepção de espaços signicos representacionais, inseridos em um processo dinâmico de interação epistêmica.

\section{DISCUSSÃO: A FENOMENOLOGIA PEIRCEANA E A TEORIA DE FUNÇÕES PRÓPRIAS E TELEOLOGIA DE MILLIKAN}

Na visão de Peirce, o universo em suas manifestações segue numa dinâmica contínua e evolutiva, com características que abrangem o estabelecimento de condições de inteligibilidade de sua ordenação e conduta. Mediante a relação entre mente e mundo, entra em ação uma habilidade da mente que capta sugestões de sentido, organizando-as numa forma sequencial e inteligível (CP 1.183), em que o absolutamente incognoscível não tem pertinência, ou seja, seria absolutamente impensável (CP 5.310, 313). 
$\mathrm{Na}$ argumentação de Peirce (CP 1.409), a mente humana está inserida no cosmos em relação conjunta com os elementos essenciais que participam de sua formação, e são partes estruturais deste mesmo cosmos. Os elementos essenciais que compõem o universo, segundo Peirce, são três: o acaso, a lei e a tendência para a formação de hábitos, correspondentes em mesma ordem às categorias que compõem a realidade fenomênica (primeiridade, secundidade, terceiridade). O mundo se constitui por meio da combinação destes elementos.

A ordem e regularidade surgem do acaso, no sentido de expressar o que é espontâneo e criador. Em conformidade com a lei geral do cosmos (tendência à formação de hábito), elementos se combinam com tendência a constituir-se em uma "forma". Ou seja, a constituição de um hábito se configura na emergência de um padrão, que, a princípio, advém do acaso. Nesse sentido, o processo de conhecimento se desenvolve no reconhecimento deste padrão formado. No entanto, os padrões que emergem, na realidade não se mantêm infinitamente, pelo contrário, seguem em um processo contínuo e evolutivo de permanente complexificação.

Para Peirce, na continuidade deste processo evolutivo (complexificação) do cosmos há uma "quebra" no padrão emergido, que pode ser radical - desembocando numa outra nova forma, ou branda - reformulando o padrão anterior. Portanto, o mesmo processo se realiza novamente por meio da ação do acaso que possibilita a quebra de um padrão anteriormente instaurado, trazendo consigo a novidade. Este movimento se repete de modo continuamente evolutivo (CP $7.566,6.103,6.169)$. Todo este processo evolutivo é colocado por Peirce em relação com as categorias fenomenológicas, categorias estas que são classificadas de acordo com o modo como as coisas se tornam aparentes no mundo.

Peirce (CP 1.300-353) $)^{1}$ explica que o universo pode ter surgido de um estado espontâneo em que não havia regularidade alguma. $O$ estado aparente se inicia em um "primeiro", desembocando em outros dois estados correspondentes: a um "segundo" e a um "terceiro". As categorias fenomenológicas configuram os modos de apresentação dos componentes que fazem parte do universo da experiência, ou seja, da realidade como ela aparece. As três categorias estão intimamente relacionadas umas às outras, de modo a não serem redutíveis, ou seja, não encontram-se isoladas no plano da experiência; por exemplo, não há um estado puro de primeiridade, de puro acaso, no plano da experiência.

Nas palavras de Peirce, "primeiridade é o modo de ser daquilo que é tal como é, positivamente e sem referência a outra coisa qualquer" (CP 8.328). Esta categoria possui características de não resultar em uma regularidade, e também não há nada que lhe seja anterior, pois se trata de um primeiro estado das coisas (CP 1.161), estado de pura espontaneidade.

A secundidade se caracteriza pela relação reativa entre um primeiro e um segundo. Esta categoria tem no seu modo de apresentação o fato objetivo, percebido nas relações de manifesta da ação e reação, pela resistência e esforço. Na categoria da secundidade há uma experiência de rompimento, de alteridade. No entanto, o aprendizado que envolve uma percepção de regularidade pode evoluir para um estado de generalização, que remete à terceira categoria fenomenológica. Esta terceira categoria fenomenológica torna-se aparente sobre o caráter necessário da generalidade.

Peirce argumenta que "a generalidade é, ainda, um ingrediente indispensável da realidade; porque a mera existência individual, ou atualidade, sem qualquer regularidade é uma nulidade. Caos é puro nada". (CP 5.431). Como apontado anteriormente, a categoria da terceiridade se constitui no terreno da regularidade, da generalidade e da lei, que se manifesta na relação implicada com um segundo e um terceiro.

A classificação destas três categorias fornece subsídios para a distinção geral das aparências das coisas, ordenadas em referências que se articulam junto ao acaso, formando

\footnotetext{
${ }^{1} \mathrm{~A}$ exposição sobre a fenomenologia desenvolvida por Peirce encontra referência em vários textos dispostos no $\mathrm{CP}$, em que serão retiradas informações de outras passagens do documento referenciado, acompanhado de notação.
} 
padrões, que possibilitam uma identificação de regularidade, consequentemente de inteligibilidade por meio de generalizações.

Na filosofia de Peirce, há uma correspondência entre a compreensão da forma da lei e a influência desta lei sobre o modo processual do pensamento. Como descreve Peirce:

Assim como as mais antigas e algumas das mais recentes especulações ela deveria ser uma Filosofia Cosmogônica. Ela deveria supor que no começo infinitamente remoto - existia um caos da sensação [ou sentimento] não personificada [não personalizada], a qual sem ter conexão ou regularidade não poderia propriamente existir. Essa sensação jogando aqui e ali em pura arbitrariedade poderia ter iniciado o germe de uma tendência generalizadora. Seus outros jogares seriam evanescentes, mas isso teria uma virtude crescente. Assim, a tendência ao hábito começaria; e a partir daí, com os outros princípios da evolução, todas as regularidades do universo poderiam estar envolvidas. Naquele tempo, contudo, um elemento de puro acaso sobrevive e permanecerá até que o mundo se torne um sistema perfeito, racional e simétrico, no qual a mente está por fim cristalizada em uma distância infinitamente futura. (CP 6.33).

Para dar sequência à evolução, a ação do acaso proporciona um fluxo de variedade na formação de novos hábitos, em que podemos pensar em uma teoria de mentes como sistemas semióticos enquanto uma realidade de representação pragmaticista.

Podemos iniciar a apresentação da Teoria de Função Própria proposta por Millikan retomando seus argumentos sobre a distinção dos conceitos de substância e propriedade. $\mathrm{O}$ intuito é de tomar como ponto de partida os conceitos constitutivos para a formulação desta teoria, desembocando na apresentação da relevância de evocar a noção de função para o contexto da natureza do significado.

A revisão sobre o conceito de identidade está posto em seu trabalho On clear and Confused Ideas (2000). De forma sucinta, sua argumentação sugere que substâncias possuem instanciações com essência comum, ou seja, são formadas de material semelhante. Sendo assim, substâncias foram pensadas, ao longo da tradição, como coleção de propriedades no esquema inferencial que se estrutura sobre a configuração de sujeito-predicado. Outro padrão recorrente ao longo da tradição racionalista é o de tomar como modelo confiável de crença justificada a configuração do conceito em sua forma proposicional, em sequencia de premissas e consequente (sendo o consequente a ratificação de sua validade). Segundo a autora, esse modelo não absorve o que é entendido como erro, ou seja, há dois caminhos, ou a proposição é válida ou não é válida. No entanto, a realidade não se apresenta aos nossos sentidos desta forma, há outros elementos que devem ser considerados como a natureza imagética, imagem não é "certa" ou "errada", sua natureza requer um tipo de juízo expandido.

Por meio de um sistema de economia cosmogônico, as experiências possuem sentido quando possuem função. Millikan reconhece substância e propriedades de substâncias como informações inseridas no tempo/espaço. As condições dos eventos são distintas das condições proposicionais, pois, no caso da primeira, o modelo de causalidade sequenciada não se aplica, pois pode haver múltiplas causas a desembocarem em um mesmo evento, enquanto que na representação linguística proposicional a sequencia é estabelecida por meio de regras que ordenam as condições de análise desta mesma linguagem. Em outro dizer, as regras que operam sobre as representações de linguagem proposicional são distintas das que atuam sobre a realidade. Além do mais, segundo a fenomenologia peirceana, as categorias fenomênicas estão indissociavelmente imbricadas, logo, a forma com que representamos o mundo por meio da lógica convencional é ineficiente para representar o mundo em seu estrato factual. Para tornar possível 
uma transliteração da compreensão dos signos do mundo para as teorias sobre o cosmos, Peirce propõe um sistema lógico que amplia as possibilidades da lógica clássica, a saber, a semiótica.

Neste contexto, Peirce e Millikan tomam pontos de partida distintos. Ela apresenta um modelo naturalista de explicação da emergência do significado, porém, que mantem relações similares à proposta peirceana, recorrendo à teoria geral dos signos ao abordar o conceito de Ícones Intencionais. Sofia Miguens apresenta, em seu artigo Dennett, Millikan e o Teleofuncionalismo (1998), os conceitos basilares propostos por Millikan ao desenvolver sua Teoria da Função Própria, trazendo à tona um exemplo que denota as implicações presentes na representação proposicional em relação à leitura de realidade.

Segundo a Teoria de Funções Próprias de Millikan a linguagem e pensamentos humanos correspondem àquilo para o qual foram projetados. Em outro dizer, a Função apresenta uma concepção de linguagem e pensamento como categorias naturais. Neste sentido, as questões de função não podem ser desarticuladas de uma teoria da linguagem, como ocorre com a representação tradicional de proposições.

Outro aspecto comum abordado por Peirce e Millikan é a incorporação do erro inserido no processo contínuo de crescimento da mente e do cosmos. Ambos, em seus sistemas teóricos, não categorizam o erro como do domínio de falsidade. Grosso modo, segundo a configuração do sistema peirceano, o erro corrobora para a identificação da alteridade, inserido na dinâmica em que a expectativa não é satisfeita e se percebe a presença de anomalia.

\section{CONCLUSÃO}

Retornando às categorias fenomenológicas apresentadas por Peirce, há uma correspondência das mesmas que conecta cada uma das categorias ao plano da inteligibilidade ${ }^{2}$. Em termos peirceanos, podemos descrever que a atribuição de sentido aquieta um desconfortável estado de dúvida, constituindo, assim a base das novas ações. Nesse contexto, o erro corrobora para a identificação de um segundo, e aparece como presença da anomalia. Nas palavras de Peirce: "A essência da crença é a criação de um hábito; e diferentes crenças distinguem-se pelos diferentes modos de ação a que dão origem" (CP 5.398). O hábito só costuma ser quebrado, quando diante de uma anomalia, em que os resultados alcançados anteriormente não se efetivam mais. Novamente há uma convergência dos sistemas propostos por estes autores, em perspectiva teleológica. Para Peirce, os hábitos são estabelecidos tendo em vista a disposição para agir, na medida em que esteja em conformidade com a "verdade" ${ }^{3}$ da crença, ratificando o hábito de conduta. Enquanto identidade da crença, o hábito de ação é, a princípio, o critério para avaliar a diferença entre crenças. Tanto a clareza de ideias quanto a escolha no modo da adoção de uma crença são avaliados com vistas da execução de uma ação mais adequada. No entanto, daqui não se segue que o pensamento seja sinônimo de significado ou mesmo de linguagem, porém que há uma imbricação nestas categorias que atuam como substrato para a emergência de significação.

Se os significados das palavras se alteram na sua natureza interna, então a relação entre o pensamento e a palavra também se modifica. Para compreender a dinâmica dessa relação, complementamos a abordagem fenomenológica do nosso estudo de base com a análise funcional da linguagem feita por Millikan. Examinar o papel do significado no processo de pensamento envolve a aplicação de inúmeros usos da linguagem e não há como privilegiar análise de um em detrimento de outro.

A concepção do significado das palavras como unidade simultânea do pensamento generalizante, e como prática pública, é de grande relevância para o estudo relacional sobre a conexão entre pensamento e mundo. Por meio desta abordagem, e para o momento exíguo,

\footnotetext{
${ }^{2}$ No sentido peirciano, inteligibilidade está associada à noção de razoabilidade.

${ }^{3} \mathrm{O}$ conceito de verdade, neste contexto, está na adequação de sua correspondência ao real, tendo em vista a aplicação do método escolhido para o estabelecimento da crença, em que Peirce aponta como mais eficaz o Método Científico.
} 
intentamos demonstrar que existe um sistema dinâmico de significação em que a ação manifesta, por meio da e na linguagem e ação, em unidade indissociável, está conectada com a porção de realidade a que cada uma delas se refere em um dado contexto.

No caso do sistema apresentado por Millikan, pode haver equívocos ao determinar conceito sobre a substância, como por exemplo, ao utilizar o conceito referente à $\mathrm{P}$, identificandoo erroneamente a alguma substância que apresente $S$, ou seja, pode haver falha quanto ao referente, pois um único conceito pode referir-se a duas substâncias, por exemplo. Neste pondo, Millikan segue em uma construção argumentativa em que a identificação de uma substância encontra-se em mesmo plano de validade de outras formas de classificá-la.

Em outro dizer, na argumentação de Millikan ${ }^{4}$ o paralelismo entre mente e mundo é delineado por alguns limites, como na distinção entre valor Real e Referência, considerando o fato de que no plano dos fatos, as funções são realizadas de modo múltiplo.

Mingues descreve que a partir da análise do sentido de negação de Millikan, ela apresenta de modo original a função da negatividade, ou seja, da contrariedade e da contradição como informações que restringem as possibilidades de determinação da identidade. Os objetos no mundo irão "dizer" o que eles não são, limitando sua determinação e taxionomia, de modo que não podem ser encerrados em um esquema de significação delimitado. Ou seja, sua "determinidade" é apresentada como consequência deste teor de negação.

Neste sentido, as frases de linguagem pública apresentam ações de identificação de referentes em que o valor de verdade poderia existir fora do referente, mas da ordem de descrições indefinidas, ligadas às explicações das Funções Próprias. Este tipo de modelo traz a significação para o uso cotidiano da linguagem comum, em que no uso concreto das expressões são criadas confusões, como também equívocos, falsas analogias, semelhanças superficiais; Millikan absorve esses elementos como parte da fundamentação da Teoria de Função Própria, absorvendo a noção de "erro" como parte funcional do sistema de significação.

\section{REFERÊNCIAS}

BARRENA, Sara F.. La Creatividad em Charles S. Peirce: Abduccion e

razonabilidad. 452 páginas. Tese de Doutorado. Universidade de Navarra. Pamplona, 2003.

IBRI, I. A. Kósmos Noëtós: a arquitetura metafísica de Charles S. Peirce. São Paulo: Perspectiva, 1992 (Coleção estudos; v. 130).

MILLIKAN, Ruth 1987. Language, Thought, and Other Biological Categories. Cambridge: MIT Press.

MILLIKAN, Ruth 1989. “Biosemantics”, Journal of Philosophy (86), pp.281-297.

MIGUENS, Sofia 1998. Dennett, Millikan e o teleofuncionalismo. In: Revista Portuguesa de Filosofia. (54), pp. 467-509.

PEIRCE, C. S. 1935, 1958. Collected Papers of Charles Sanders Peirce. Ed. Hartshorne, Weiss \& Burks. Cambridge: Harvard Univ. Press.

PEIRCE, C. S. 1995. Semiótica. São Paulo: Perspectiva.

PEIRCE, C.S. 2008. Ilustração da lógica da ciência. Trad. Renato Rodrigues Kinouchi. São Paulo: Idéias \& Letras.

\footnotetext{
${ }^{4}$ Apud MIGUENS, 1998, p. 497.
} 
PEIRCE, C. S. Semiótica. São Paulo: Perspectiva, 1995.

PEIRCE, C. S. Ilustração da lógica da ciência. Trad. Renato Rodrigues Kinouchi. São Paulo: Ideias \& Letras, 2008.

SANTAELLA, L. Produção de Linguagem e Ideologia._2.ed. São Paulo: Cortez, 1996.

SANTAELLA, L. O método anticartesiano de C. S. Peirce. São Paulo: Ed. UNESP, 2004. https://doi.org/10.7476/9788539303236

SILVEIRA, L. F. B. Charles S. Peirce e a contemporânea filosofia da ciência. In: Trans/Form/Ação. Revista de Filosofia, V, 14, 1993. PP.45-52.

SILVEIRA, L. F. B. Curso de Semiótica Geral. São Paulo: Quartier Latin, 2007. 